\title{
Ultrafast Dynamics of Metal Complexes of Tetrasulphonated Phthalocyanines
}

\author{
Arkadiusz Jarota, ${ }^{\dagger}$ Marc Tondusson, $^{\ddagger}$ Geoffrey Galle, ${ }^{\ddagger}$ Eric Freysz, ${ }^{\ddagger}$ and Halina Abramczyk ${ }^{\dagger}$ \\ ${ }^{\dagger}$ Institute of Applied Radiation Chemistry, Laboratory of Laser Molecular Spectroscopy, Technical University of Lodz, \\ Wroblewskiego 15, 93590 Lodz, Poland \\ ${ }^{\ddagger}$ Laboratoire Ondes et Matière d'Aquitaine (LOMA), Université Bordeaux 1, UMR CNRS 5798, 351 Cours de la Libération 33405 \\ Talence Cedex, France
}

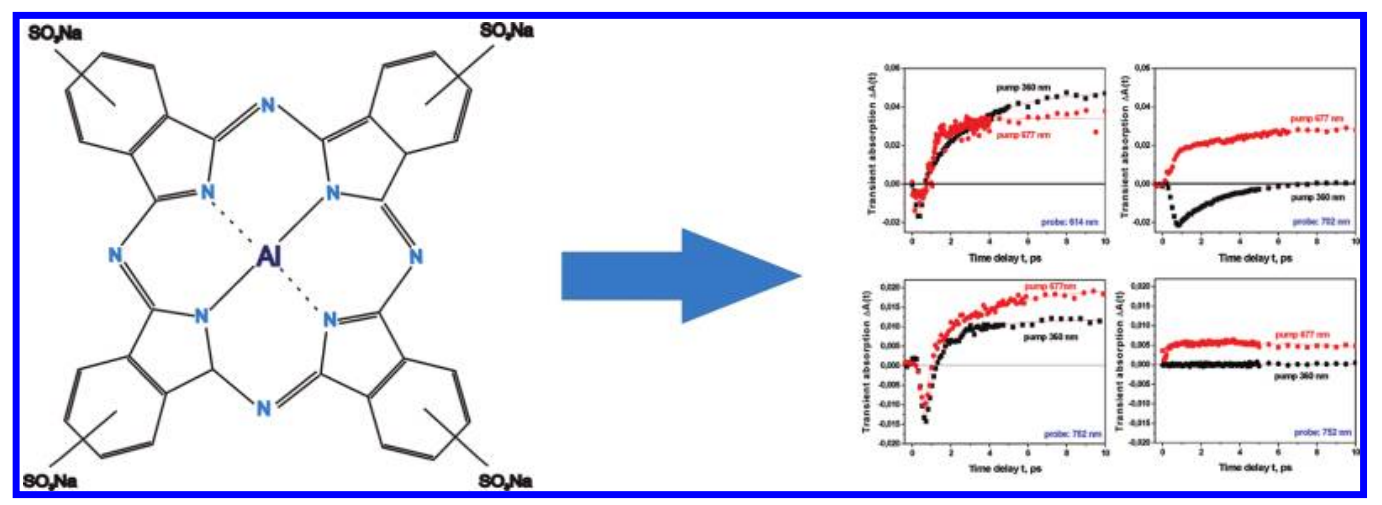

\begin{abstract}
A promising material in medicine, electronics, optoelectronics, electrochemistry, catalysis, and photophysics, tetrasulphonated aluminum phthalocyanine $\left(\mathrm{AlPcS}_{4}\right)$, is investigated by means of steady state and time resolved pump-probe spectroscopies. Absorption and steady state fluorescence spectroscopy indicate that $\mathrm{AlPcS}_{4}$ is essentially monomeric. Spectrally resolved pump-probe data are recorded on time scales ranging from femtoseconds to nanoseconds. The nature of these fast processes and pathways of the competing relaxation processes from the initially excited electronic states in aqueous and organic

(dimethyl sulfoxide) solutions are discussed. The decays and bleaching recovery have been fitted in the ultrafast window $(0-10 \mathrm{ps})$ and later time window extending to nanoseconds $(0-1 \mathrm{~ns})$. While the excited state dynamics have been found to be sensitive to the solvent environment, we were able to show that the fast dynamics is described by three time constants in the ranges of $115-500 \mathrm{fs}, 2-25 \mathrm{ps}$, and 150-500 ps. We were able to ascribe these three time constants to different processes. The shortest time constants have been assigned to vibrational wavepacket dynamics. The few picosecond components have been assigned to vibrational relaxation in the excited electronic states. Finally, the 150-500 ps components represent the decay from $S_{1}$ to the ground state. The experimental and theoretical treatment proposed in this paper provides a basis for a substantial revision of the commonly accepted interpretation of the Soret transition (B transition) that exists in the literature.
\end{abstract}

\section{INTRODUCTION}

Phthlocyanines and metallophthalocyanines are involved in many biological, chemical, and physical processes. The pos sibility to tailor and modify their properties such as absorption, emission, nonlinear optical responses, polarizability, and dipole moment make them extremely important materials in many disciplines of research like biomedicine, electronics, optoelec tronics, electrochemistry, photophysics, and catalysis. The diversity of their functions is due in part to the variety of metals that bind in the "pocket" of the phthalocyanine ring system. They have been proven to be efficient photosensitizers in a number of chemical and photochemical processes, especially photodynamic therapy (PDT).

PDT of cancer is a promising application, particularly for small and superficial tumors as well as benign skin and mouth disorders. At present, PDT is also being tested in the clinic for use to treat cancers of the brain, head and neck, lung, pancreas, intraperitoneal cavity, skin, prostate, and breast. ${ }^{1-8}$ Recently, the targeted PDT technique has been tested on breast cancer cells. $^{9-11}$ aluminum tetrasulphonated phthalocyanine $\left(\mathrm{AlPcS}_{4}\right)$ has been used in clinical trials ${ }^{12-14}$ because its triplet state has the ability to react with molecular oxygen to produce highly reactive singlet oxygen. Despite the medical applications, a growing numbers of phthalocyanines play an important role as low gap semiconducting materials. ${ }^{15}$

The processes of energy dissipation in phthalocyanines occurring on the nanosecond time scale, such as internal con version, fluorescence, intersystem crossing, and the triplet forma tion, have been studied in many papers. ${ }^{16-35}$ There are many fewer papers reporting on primary events in phthalocyanines 
occurring on femtosecond and picosecond scales, ${ }^{23,36-43}$ which are particularly important in thin films. The effects of aggre gation on the absorption and emission spectra of metalloph thalocyanines in the liquid solutions are well documented ${ }^{44-53}$ but much less information has been accumulated on the solid phases. The films of phthalocyanines become relevant in advanced devices like electrochromic displays, optical limiters, light emitting diodes, recordable digital discs, organic conductors, lasers, nonlinear optical elements, and so forth. In these applications, properties such as conductivity, optical absorbance, and photoconductivity in the solid state phase are important. ${ }^{15,54}$

In this paper, $\mathrm{AlPcS}_{4}$ has been chosen to serve as a model phothosenistizer to study the efficiency of primary processes occurring upon excitation of the chromophore that lead to the triplet generation.

In this paper, we wish to elucidate processes responsible for fast dynamics of $\mathrm{AlPcS}_{4}$ occurring on the time scale from femtoseconds to nanoseconds monitored by the pump-probe transient absorption spectroscopy when induced by femto second laser pulses centered at 677 and $360 \mathrm{~nm}$, corresponding to the absorption maxima of the Soret band and the Q band, respectively.

\section{EXPERIMENTAL SECTION}

Aluminum phthalocyanine chloride tetrasulphonic acid was purchased from Frontier Scientific, Inc. (AlPcS 834). Dimethyl sulfoxide (DMSO) was purchased from Sigma Aldrich (34869). They were used without further purification. Water was deionized before preparing the solutions. Briefly, Scheme 1 illustrates the

Scheme 1. Method Used for Synthesis of $\mathrm{AlPcS}_{4}$ via Sulphonation of the Non Sulphonated Phthalocyanine

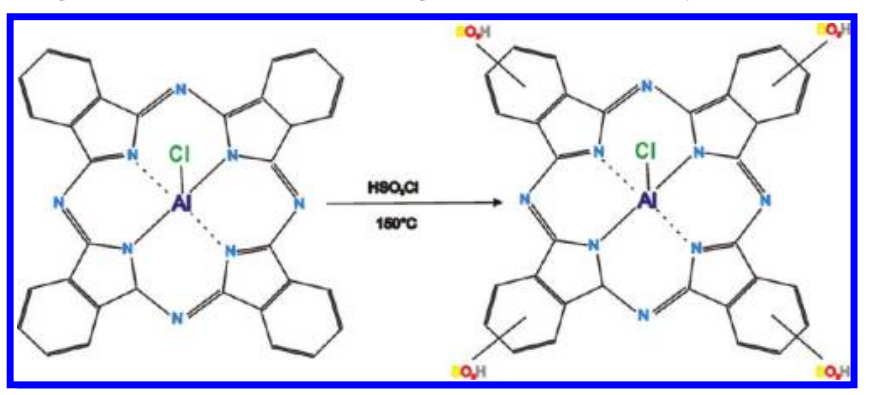

method used for synthesis of $\mathrm{AlPcS}_{4}$ via sulphonation of the nonsulphonated phthalocyanine. This method leads to a large number of regioisomers.

Steady-State Emission Measurements. Emission spectra were measured with a Ramanor U1000 (Jobin Yvon) and Spectra Physics 2017 04S argon ion laser operating at $514 \mathrm{~nm}$ at a power of $100 \mathrm{~mW}$. The spectral slit width was $6 \mathrm{~cm}^{-1}$, which corresponds to the $500 \mu \mathrm{m}$ mechanical slit of the spectrometer; a $\lambda / 4$ wave plate was used to change the linear polarization into the circular one to avoid the different polar ization sensitivity of the gratings. The interference filter has been used to purify the laser line by removing additional natural emission lines that interfere with the Raman lines, especially in the case of the solid samples.

Steady-State UV-Vis Absorption Measurements. UV-vis absorption electronic spectra were measured with Varian Cary 5E spectrophotometer in 2 and $0.10 \pm 0.005 \mathrm{~mm}$ detachable quartz cells (Hellma). The spectra were recorded at $293 \mathrm{~K}$ for the aqueous solutions and in DMSO at con centrations of $c=10^{-5}, 10^{-4}$, and $10^{-3} \mathrm{M}$.
Pump-Probe Transient Absorption Spectroscopy. The source of the femtosecond pulses was a mode locked titanium sapphire femtosecond laser (MIRA, Coherent, $800 \mathrm{~nm}$, $76 \mathrm{MHz}, 9 \mathrm{~nJ},<200 \mathrm{fs}$ ) pumped with a diode pumped solid state laser (VERDI V5, Coherent, $532 \mathrm{~nm}$ ). The fundamental beam was amplified with a Ti:Sapphire regenerative amplifier (Coherent Legend USP, $800 \mathrm{~nm}, 1 \mathrm{kHz}, 3 \mathrm{~mJ}, 50 \mathrm{fs}$ ). The regenerative amplifier was pumped with a diode pumped $\mathrm{Nd}$ :YLF laser (JADE, Thales Laser, $527 \mathrm{~nm}, 1 \mathrm{kHz}, 20 \mathrm{~mJ}$, $<200 \mathrm{~ns}$ ). The pulse was split in two and further amplified in a dual single pass amplifier (Coherent Elite Duo, $800 \mathrm{~nm}, 1 \mathrm{kHz}$, $2 \times 4.5 \mathrm{~mJ}, 50 \mathrm{fs}$ ). This amplifier was pumped by a high power $\mathrm{Nd}$ :YLF laser (Evolution, Coherent, $527 \mathrm{~nm}, 50 \mathrm{~mJ},<200 \mathrm{~ns}$ ). The output of the laser system was split, and two $1 \mathrm{~mJ}$ laser pulses were used to pump two optical parametric amplifiers (OPA, model TOPAS from Light Conversion). These OPA combined by frequency conversion modules generate femto second pulses tunable in the 300 and $2600 \mathrm{~nm}$ ranges. The energy of the pump pulse was adjusted to $2 \mu \mathrm{J}$ in water experiments and $700 \mathrm{~nJ}$ or less in experiments with DMSO. The energy of the probe pulse was at least 100 times lower than the energy of the pump pulse. The pump and probe pulses were overlapped on a $1 \mathrm{~mm}$ optical path of a cell containing the $\mathrm{AlPcS}_{4}$ solution. The solution was circulated in the cell by a magnetic stirrer in order to minimize the thermal lensing and photoquenching effects. The time delay $t$ between the pump and probe pulses was adjusted by a motorized translation stage that has a spatial resolution of $1.5 \mu \mathrm{m}$. Transient absorption signals was measured with two silicon photodiodes (Thorlabs, TDS 1000) placed before and after the sample, which measure initial $\left(I_{0}\right)$ and the transmitted intensity of the probe beam $\left(I_{t}\right)$ respectively. The $I_{0}$ was normalized with respect to the intensity of the pump beam, which was measured with the same type of the photodiode. The absorption signal $S(t)$ was calculated as $\log \left(I_{0} / I_{\mathrm{t}}\right)$ The transient absorption signal $\Delta A(t)$ was computed by subtracting the absorption signal measured with and with out the pump pulse. For that reason, the pump beam was chopped at $40 \mathrm{~Hz}$. The typical measurement error of $\Delta A$ was better than $10^{-3}$.

Computational Method. Geometry optimizations have been performed using Gaussian 03 software ${ }^{55}$ on the DFT level with the B3LYP hybrid functional and $631 \mathrm{G}(\mathrm{d})$ basis set. Additionally, to get more insight into electronic transitions, we have carried out the TD DFT calculations at the B3LYP 6 $31 \mathrm{G}(\mathrm{d})$ level.

\section{RESULTS}

Steady-State Absorption and Emission Measurements. The steady state absorption spectra of $\mathrm{AlPcS}_{4}$ in water and DMSO as a function of concentration are shown in Figure 1. The $\mathrm{Q}$ band $\left(\mathrm{S}_{0}\left(\mathrm{a}_{2 \mathrm{u}}\right) \rightarrow \mathrm{S}_{1}\left(\mathrm{e}_{\mathrm{g}}\right)\right.$ transition) has a sharp maximum at $678 \mathrm{~nm}$ as well as weaker bands to the blue side with maxima at 643 and $607 \mathrm{~nm}$. The shape, the positions of the absorption maxima, and the intensity of the bands at 643, 607 , and at $678 \mathrm{~nm}$ are normalized to the maximum of the band at $678 \mathrm{~nm}$. One can see that the absorption bands are very similar in the concentration range of $10^{-5}-10^{-3} \mathrm{M}$, indicating that $\mathrm{AlPcS}_{4}$ molecules are dominated by a monomeric form in both solvents.

The fluorescence spectrum presented in Figure $2\left(\lambda_{\text {exc }}=514 \mathrm{~nm}\right)$ shows an almost perfect mirror image of the absorption spectrum in the Q band region, indicating that the bands at 643 and $607 \mathrm{~nm}$ should be assigned to the vibrational progression. 


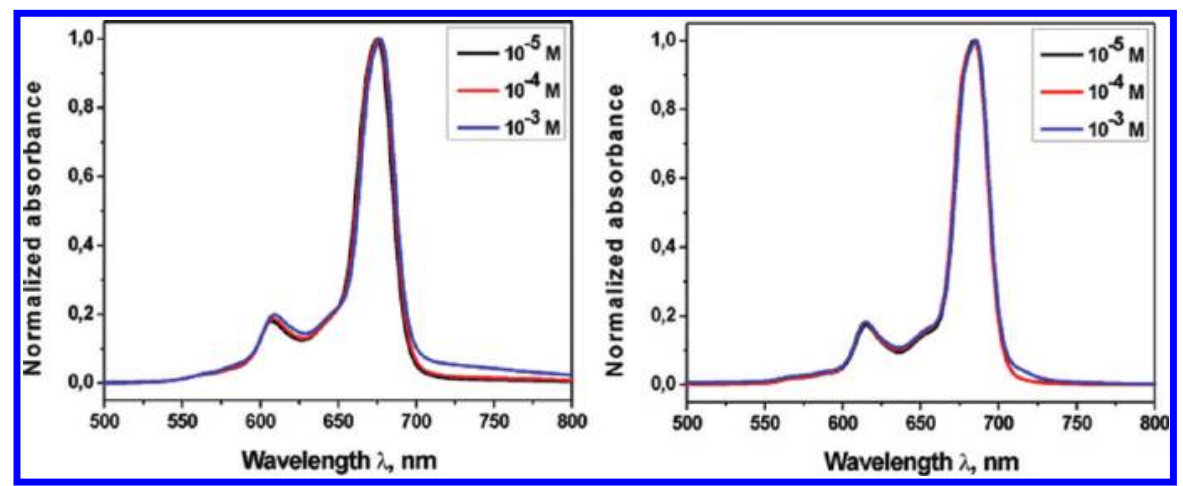

Figure 1. Normalized absorption spectra of $\mathrm{AlPcS}_{4}$ solutions in the concentration range of $10^{-5}-10^{-3} \mathrm{M}$, (a) in water and (b) in DMSO.

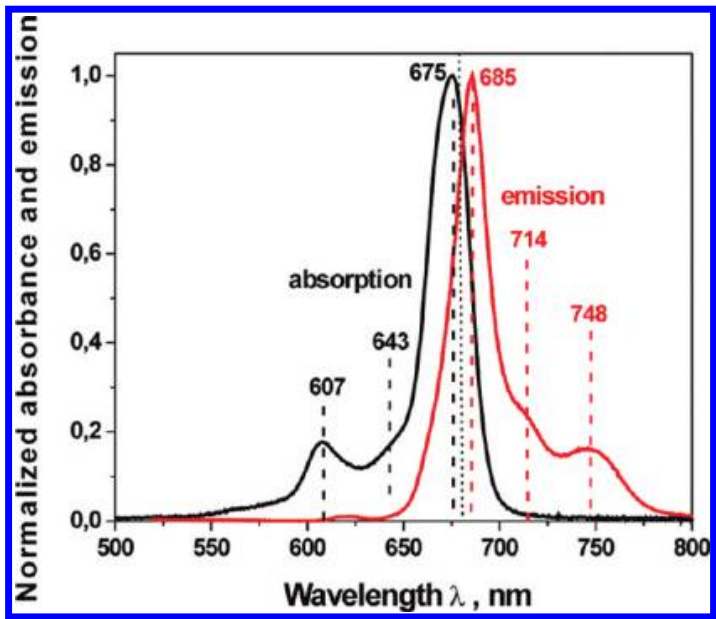

Figure 2. Normalized absorption and emission spectra of $\mathrm{AlPcS}_{4}$ in aqueous solution at a concentration of $c=10^{-6} \mathrm{M}$.

The maximum of emission at $685 \mathrm{~nm}$ provides a Stokes shift of $8 \mathrm{~nm}$. However, at higher concentrations, the fluorescence spectrum presented in Figure $3\left(\lambda_{\text {exc }}=514 \mathrm{~nm}\right)$ shows no

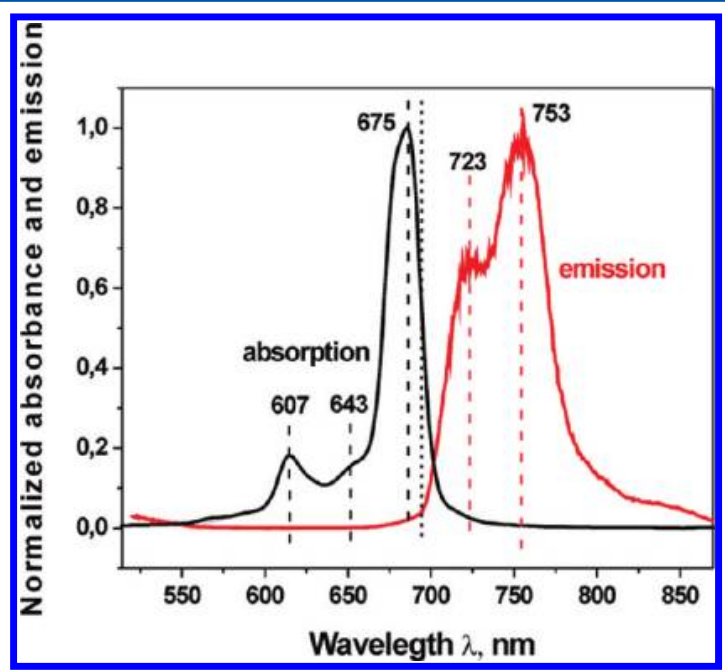

Figure 3. Normalized absorption and emission spectra of $\mathrm{AlPcS}_{4}$ in aqueous solution at a concentration of $c=10^{-3} \mathrm{M}$.

features of the mirror image of the absorption and the emission spectra in the $\mathrm{Q}$ band region, indicating that the contribution from reabsorption and aggregation leads to disturbance of the image typical for the monomeric form.
The absorption at high concentrations becomes solvent dependent. Figure 4 shows the absorption of $\mathrm{AlPcS}_{4}$ at $c=10^{-3}$

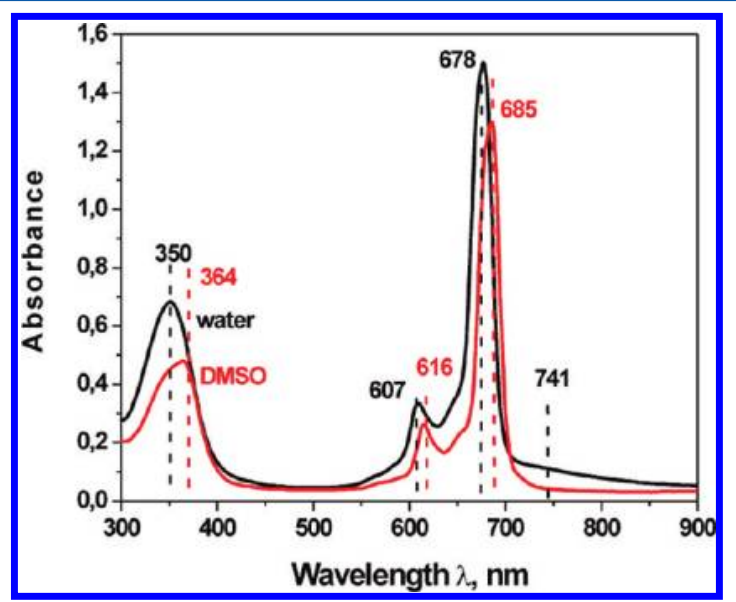

Figure 4. Absorption spectra of $\mathrm{AlPcS}_{4}$ solution in water (black line) and in DMSO (red line) for $c=10^{-3} \mathrm{M}$; optical length $=0.1 \mathrm{~mm}$.

M in DMSO and water. The band in DMSO is red shifted from 678 to $685 \mathrm{~nm}$ and is substantially narrowed relative to the absorption bands in water. The red shift in organic solvents has been attributed to a shift from aggregates toward mono mers. ${ }^{56,57}$ The results from Figure 4 indicate that the $\mathrm{AlPcS}_{4}$ molecules are more aggregated in water, while in DMSO, they are almost monomeric even at high concentrations.

Figure 5 shows the emission of $\mathrm{AlPcS}_{4}$ at $c=10^{-5}$ and $10^{-3} \mathrm{M}$ in DMSO and water. The emission spectra are much more concentration sensitive, particularly at high concentrations. The distinctions observed in the emission spectra at higher con centrations must be related to different paths of energy dissipation.

Excited-State Dynamics of AlPcS 4 in Aqueous and DMSO Solutions. $S_{0}\left(a_{1 u}\right) \rightarrow S_{1}\left(e_{g}\right)$ Transition. To get a deeper insight into the mechanisms of energy dissipation in phthalocyanines, we have monitored the excited state dynamics in aqueous and organic (DMSO) solvents upon excitation at $677 \mathrm{~nm}$, which promotes the $S_{0}\left(a_{1 u}\right) \rightarrow S_{1}\left(e_{g}\right)$ transition in the Q band (Scheme 2).

Figure 6 shows the transient absorption signals $\Delta A(t)$ of $\mathrm{AlPcS}_{4}$ in aqueous and organic (DMSO) solvents at a con centration of $10^{-3} \mathrm{M}$ as a function of the time delay $t$ in the pump-probe experiments. The molecules were excited at $677 \mathrm{~nm}$ and probed at different wavelengths (500, 572, 664, and $690 \mathrm{~nm})$. The right panel shows the results in DMSO, and the left panel 


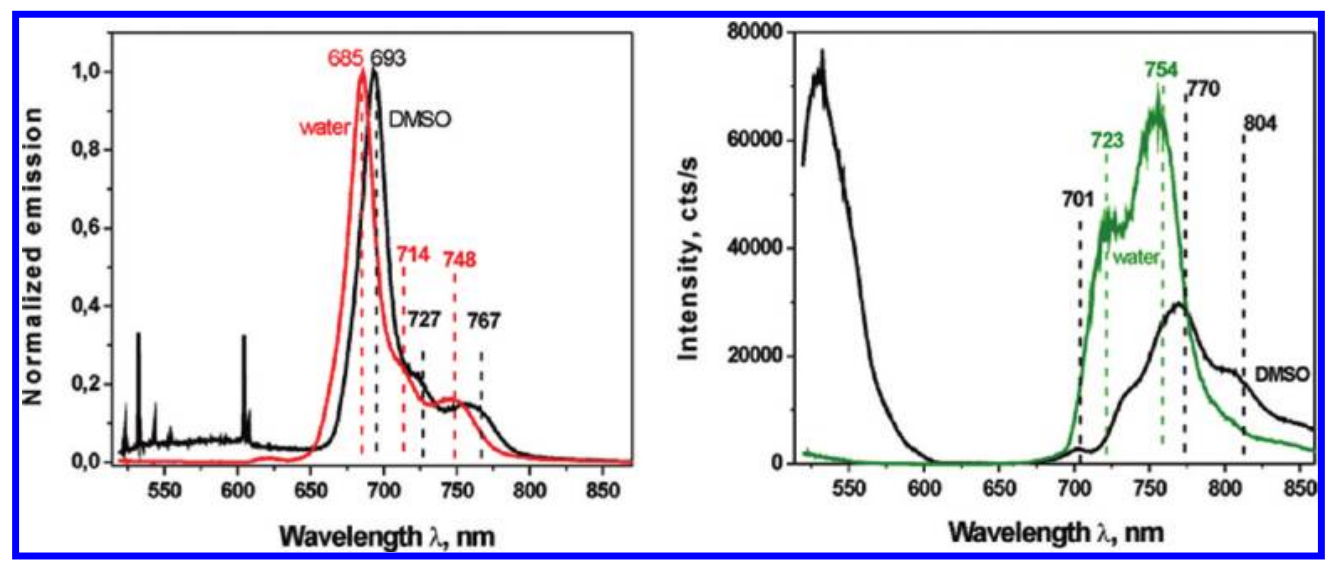

Figure 5. Emission spectra of $\mathrm{AlPcS}_{4}$ in $\mathrm{DMSO}$ and in water at $c=(\mathrm{a}) 10^{-5}$ and (b) $10^{-3} \mathrm{M}$.

Scheme 2. Excitation of the Excited Electronic States Pumped with the Pulses at 360 and $677 \mathrm{~nm}$

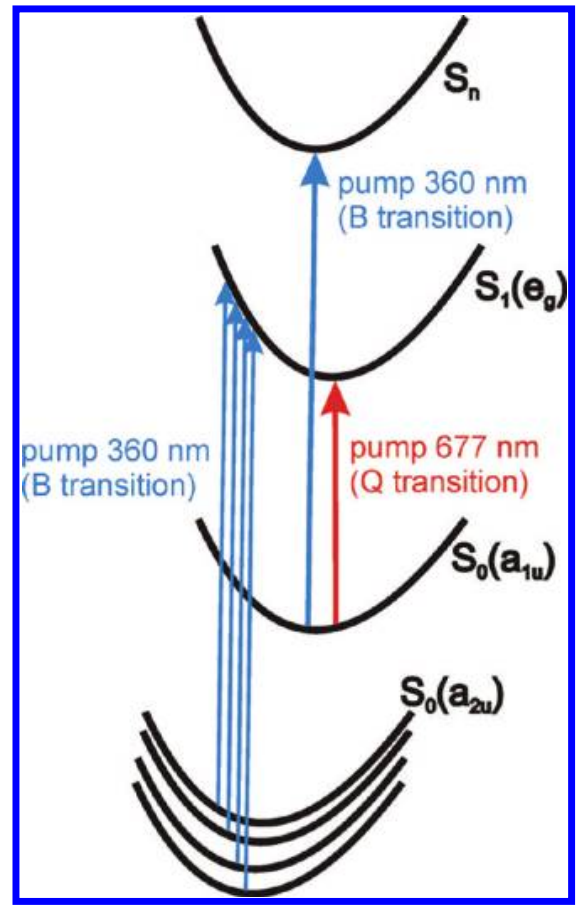

shows the results in aqueous solution. The results in Figure 6 are presented in the full time window up to $1 \mathrm{~ns}$.
Comparison between Figure $6 \mathrm{a}$ and $\mathrm{b}$ demonstrates that in DMSO, the excited state dynamics of $\mathrm{AlPcS}_{4}$ is drastically different from that in water. Directly upon excitation with the laser pump pulse at $677 \mathrm{~nm}$, a negative signal at $664 \mathrm{~nm}$ (Figure 6a) has been recorded in the aqueous solution of $\mathrm{AlPcS}_{4}$. The latter phenomenon is assigned to the bleaching of the $\mathrm{Q}$ transition. The bleach is instantaneous and is laser pulse width limited. In water, the recovery of the bleach at $664 \mathrm{~nm}$ is found to be biexponential and is fitted with time constants of $5.09 \pm 0.99$ and $203.16 \pm 18.75$ ps. It is important to notice that the recovery goes above the baseline at around 400 ps and the signal becomes positive. The time constants are of the same order as those obtained by Howe et al. ${ }^{23}$ for $\mathrm{PcS}_{4}$ and $\mathrm{ZnPcS}_{4}$ in DMSO probed at 720, 790, and $820 \mathrm{~nm}$. Even though we slightly shifted the probe wavelength, one can observe the bleaching in water (Figure 6a) but no evidence of bleaching in DMSO (Figure 6b). In DMSO, we recorded a sudden rise instead.

Figure 6a shows that the instantaneous bleach of $\mathrm{AlPcS}_{4}$ in water at $664 \mathrm{~nm}$ is accompanied by a sudden rise at $500 \mathrm{~nm}$ that is followed by decay. This decay is found to be biexponential and is fitted with time constants of $3.23 \pm 0.68$ and $304 \pm 39$ ps in water (Figure 6a) and $24 \pm 19$ and $380 \pm$ 178 ps in DMSO (Figure 6b).

Further ultrafast dynamics can be monitored in other regions of the transient absorption spectrum ( $572 \mathrm{~nm}$ in Figure 6a,b). The sudden rise at $572 \mathrm{~nm}$ is followed by a decay that is found to be biexponential and that is fitted with time constants of $3.51 \pm$ 0.50 and $220 \pm 25$ ps in water and 3.44 and $115 \pm 95$ ps in

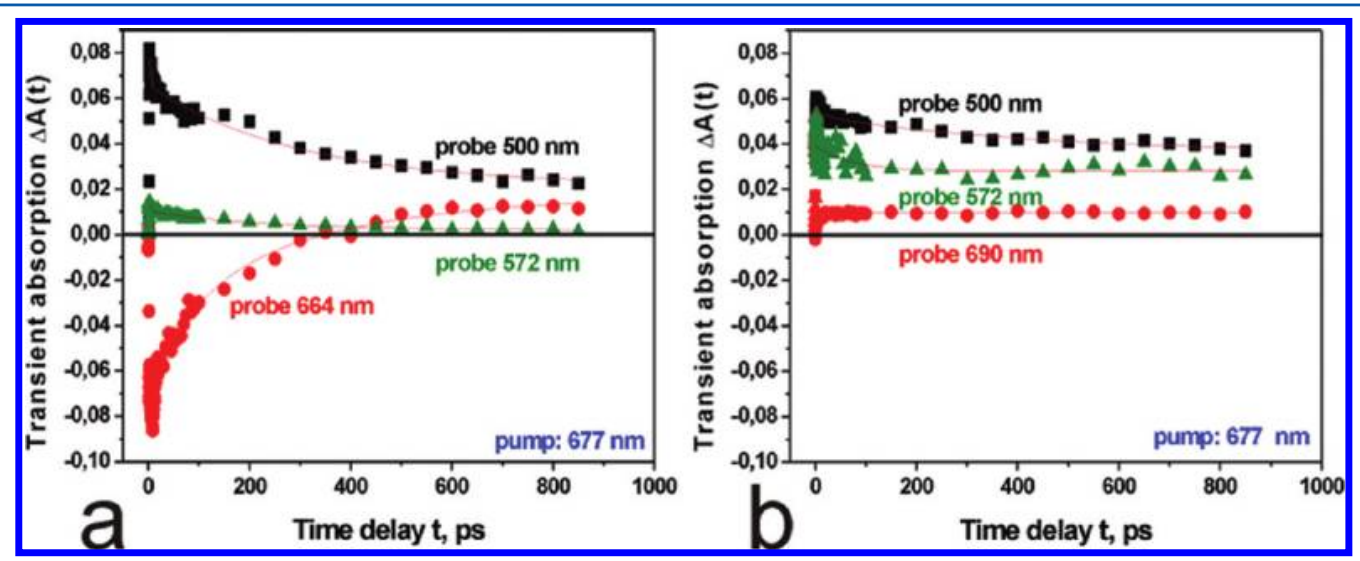

Figure 6. Transient absorption signal $\Delta A(t)$ of $\mathrm{AlPcS}_{4}$ in water (a) and DMSO (b) as a function time delay in the full time window up to 1 ns, pumped at $677 \mathrm{~nm}$ and probed at 500,572,664, and $690 \mathrm{~nm}$; concentration $=10^{-3} \mathrm{M}$. 


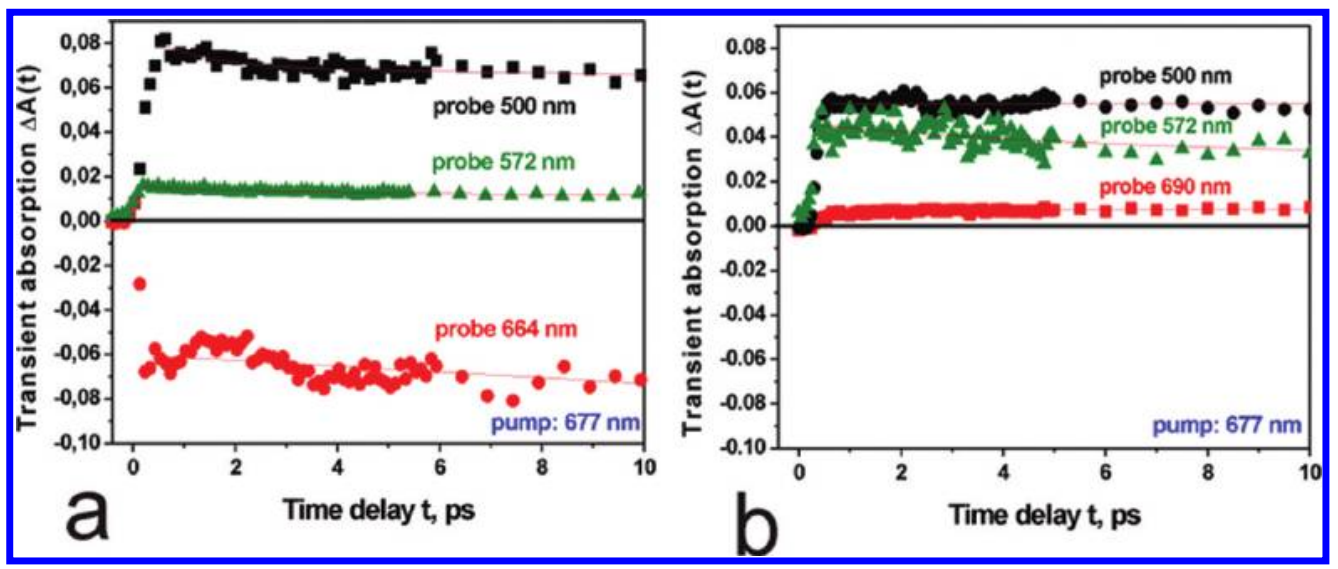

Figure 7. Transient absorption signal $\Delta A(t)$ of $\mathrm{AlPcS}_{4}$ in water (a) and DMSO (b) as a function of time delay in the early time window up to 10 ps, pumped at 677 and probed at 500,572, 664, and $690 \mathrm{~nm}$; concentration $=10^{-3} \mathrm{M}$.

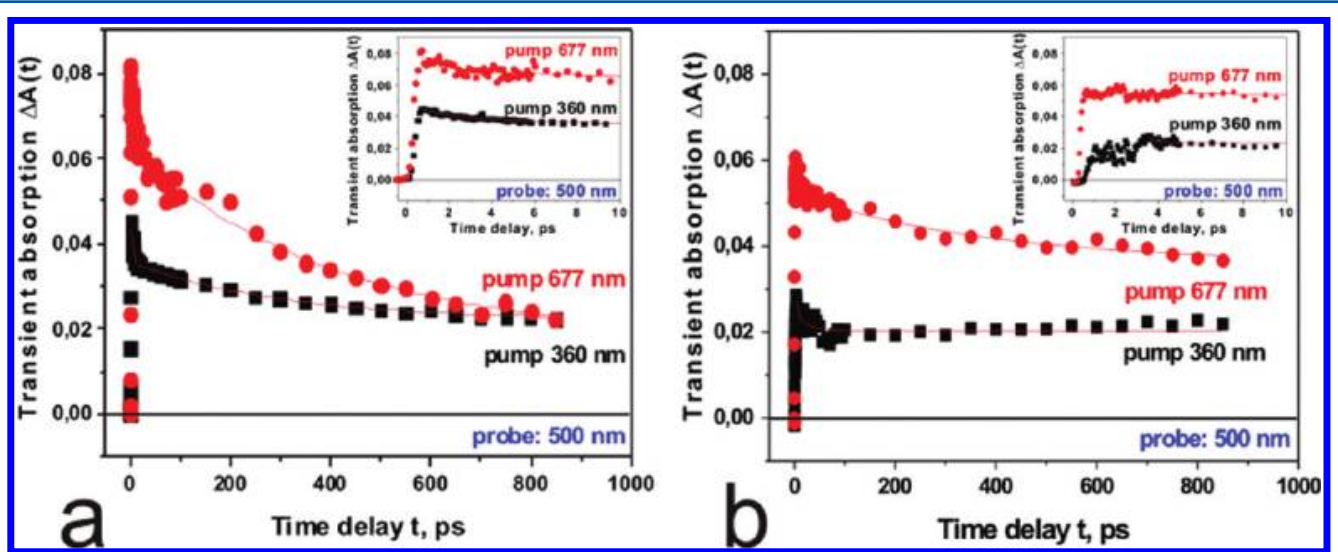

Figure 8. Transient absorption signal $\Delta A(t)$ of $\mathrm{AlPcS}_{4}$ in water (a) and DMSO (b) as a function time delay in the full time window up to $1 \mathrm{~ns}$, probed at $500 \mathrm{~nm}$, pumped at 677 and $360 \mathrm{~nm}$; concentration $=10^{-3} \mathrm{M}$. The insets show the signal $\Delta A(t)$ in the time window up to 10 ps.

DMSO, indicating that the signals observed in the range of 500-572 nm demonstrate similar features of dynamics.

Figure 7 presents the results for $\mathrm{AlPcS}_{4}$ in water (Figure 7a) and in DMSO (Figure $7 \mathrm{~b}$ ) in the early time window extending to 10 ps. The initial decays of the signal at $500 \mathrm{~nm}$ are monoexponential and can be fitted with a time constant of $244 \pm 98$ fs in water and $155 \pm 51 \mathrm{fs}$ in DMSO. The decays of the signal at $572 \mathrm{~nm}$ are monoexponential and can be fitted with a time constant of $560 \pm 94 \mathrm{fs}$ in water and $480 \pm 384 \mathrm{fs}$ in DMSO. Savolainen and co workers ${ }^{39}$ have studied $\mathrm{ZnPc}$ in DMSO $\left(0.12 \times 10^{-3} \mathrm{M}\right)$. They obtained three time constants, $250 \mathrm{fs}, 2.5 \mathrm{ps}$, and $2.9 \mathrm{~ns}$. Bearing in mind that the study in ref 39 was on $\mathrm{ZnPc}$, not $\mathrm{AlPcS}_{4}$, we nonetheless feel that a com parison is worthwhile. We find no evidence of the slow com ponent $(2.9 \mathrm{~ns})$ in our measurements of the transient absorption. The slowest component of dynamics of the order $150-500$ ps observed in our paper at different wavelengths is similar to that reported by Howe et al. ${ }^{23}$ On the other side, we find that the fast, femtosecond components obtained in this paper, which were demonstrated by the time constant of 244 (in water) and $155 \mathrm{fs}$ (in DMSO) for the $500 \mathrm{~nm}$ and of $560 \mathrm{fs}(480 \mathrm{fs})$ in water (DMSO) for $572 \mathrm{~nm}$ probing wavelengths, are similar to the time constants reported by Savolainen et al. ${ }^{39}$

$S_{0}\left(a_{2 u}\right) \rightarrow S_{1}\left(e_{g}\right)$ Transition. The pumping at $360 \mathrm{~nm}$ excites the transition $S_{0}\left(a_{2 u}\right) \rightarrow S_{1}\left(e_{g}\right)$ and/or the $S_{n}$ state (Scheme 2). Figure 8 compares the transient absorption signals $\Delta A(t)$ recorded at $500 \mathrm{~nm}$ when the sample is pumped at 677 and $360 \mathrm{~nm}$. In water, the instantaneous rise at $500 \mathrm{~nm}$, limited by the laser pulse duration, is followed by a biexponential decay with time constants of $3.23 \pm 0.68$ and $304 \pm 39$ ps for the pumping at $677 \mathrm{~nm}$ and $3.18 \pm 0.19$ and $299.38 \pm 24$ ps for the pumping at $360 \mathrm{~nm}$. In DMSO, the relevant time constants are $24 \pm 19$ and $380 \pm 17$ ps for pumping at $677 \mathrm{~nm}$ and $24.06 \pm 9.57$ and $220 \pm 180 \mathrm{fs}$ for pumping at $360 \mathrm{~nm}$. Thus, both components of the dynamics are similar for both pumping wavelengths in both solvents.

Figure 9 compares the transient absorption signals $\Delta A(t)$ of $\mathrm{AlPcS}_{4}$ at the probe wavelength of $572 \mathrm{~nm}$ in water (left panel) and in DMSO (right panel) when the sample is pumped at 360 and $677 \mathrm{~nm}$, respectively. In water, when the sample is pumped at $360 \mathrm{~nm}$, the decay of the positive signal of $\mathrm{AlPcS}_{4}$ at $572 \mathrm{~nm}$ is found to be biexponential and is fitted with time constants of $58 \pm 24$ and $614 \pm 378$ ps. However, when the sample is pumped at $677 \mathrm{~nm}$, the decay of the signal is found to be biexponential and fitted with time constants of $3.51 \pm 0.50$ and $220 \pm 25$ ps. In DMSO, the decay of positive signals of $\mathrm{AlPcS}_{4}$ at $572 \mathrm{~nm}$ is found to be biexponential and is fitted with time constants of $3.44 \pm 1.31$ and $115 \pm 81$ ps and $2.00 \pm 0.13$ and $360 \pm 152$ ps when the sample is pumped at 667 and $360 \mathrm{~nm}$, respectively. As the positive signals at 500 and $572 \mathrm{~nm}$ in Figures 8 and 9 appear instantaneously within the femtosecond time scale, we have assigned them to the excited state absorption (ESA).

Figure 10 compares the transient absorption signals $\Delta A(t)$ of the sample pumped at 360 and $677 \mathrm{~nm}$ and probed at wavelengths of 614 and $752 \mathrm{~nm}$ when $\mathrm{AlPcS}_{4}$ is dissolved in water and 702 and $752 \mathrm{~nm}$ when $\mathrm{AlPcS}_{4}$ is dissolved in DMSO. In water, directly upon excitation, instantaneous bleach (negative 


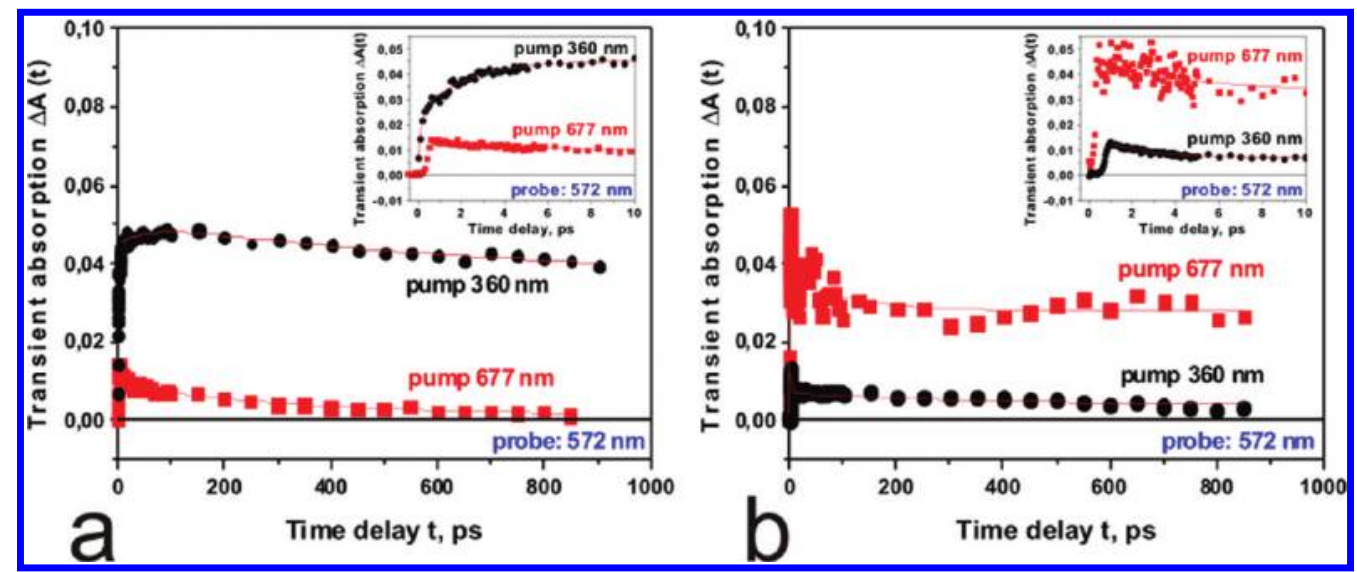

Figure 9. Transient absorption signal $\Delta A(t)$ of $\mathrm{AlPcS}_{4}$ at the probe wavelength of $572 \mathrm{~nm}$ in water (a) and in DMSO (b) for pumping at 360 and $677 \mathrm{~nm}$; concentration $=10^{-3} \mathrm{M}$. The insets show the signal $\Delta A(t)$ in the time window up to $10 \mathrm{ps}$.

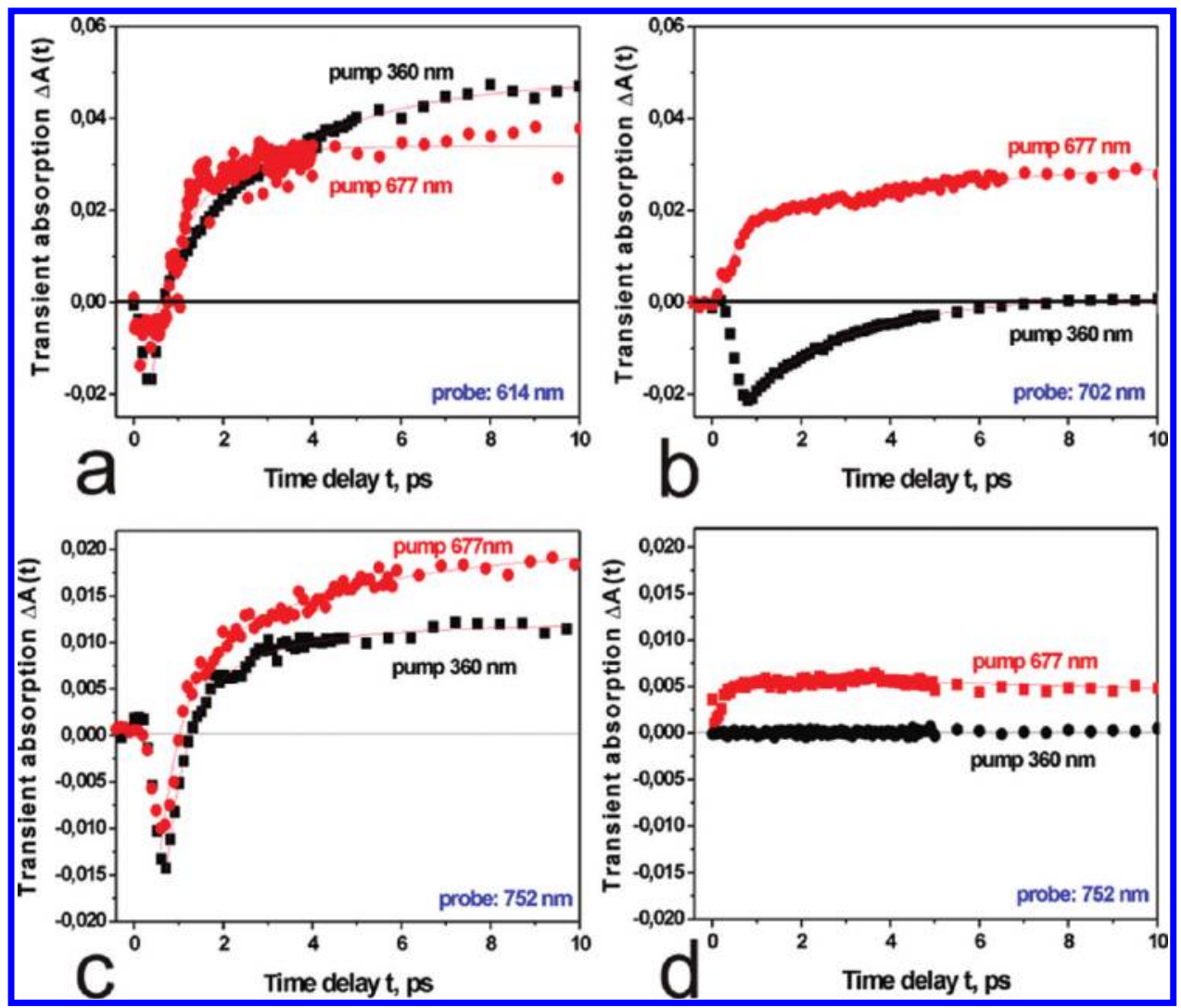

Figure 10. Transient absorption signal $\Delta A(t)$ of $\operatorname{AlPcS}_{4}$ in water $(\mathrm{a}, \mathrm{c})$ and DMSO $(\mathrm{b}, \mathrm{d})$ as a function time delay in the early time window up to $10 \mathrm{ps}$, pumped at 360 and $677 \mathrm{~nm}$ and probed at 614,702 , and $752 \mathrm{~nm}$; concentration $=10^{-3} \mathrm{M}$.

signal) is present at 614 and $752 \mathrm{~nm}$. This instantaneous bleach (laser pulse width limited) is followed by a recovery. The recovery of the bleach at $614 \mathrm{~nm}$, when the sample is pumped at $360 \mathrm{~nm}$, is found to be biexponential and is fitted with time constants of $231 \pm 26$ fs and $2.75 \pm 0.10$ ps in the early window up to 10 ps. In water, when the sample is probed at $752 \mathrm{~nm}$, the recovery of the bleach is found to be biexponential and is fitted with time constants of $490 \pm 70$ fs and $3.79 \pm 1.25$ ps for pumping at $677 \mathrm{~nm}$ and $480 \pm 60 \mathrm{fs}$ and $2.33 \pm 0.81 \mathrm{ps}$ for pumping with $360 \mathrm{~nm}$. In DMSO, the bleaching is observed only for pumping at $360 \mathrm{~nm}$. When the probe is set at $702 \mathrm{~nm}$, the bleaching is fitted by a biexponential function with time constants of $450 \pm 302 \mathrm{fs}$ and $2.45 \pm 10$ ps. Contrary, when the sample is pumped at $677 \mathrm{~nm}$ and probed at $702 \mathrm{~nm}$, one records a positive signal. Its rise is found to be fitted by a biexponential function with the time constants of $460 \pm 60$ fs and $6.12 \pm 2.12$ ps. For all of the signals presented in Figure 10, it is important to notice that the recovery signals at 614,702 , and $752 \mathrm{~nm}$ go above the baseline at around $400 \mathrm{ps}$, and the signal becomes positive. For the probe wavelength at $752 \mathrm{~nm}$, the difference in the signal in water and that in DMSO presented in Figure 10c and d is most likely due to a coincidental cancellation between the bleach and ESA $\left(S_{1} \rightarrow S_{n}\right)$.

\section{DISCUSSION}

In order to elucidate further electronic dynamics features that can be rationalized from the signals of the transient absorption 
Scheme 3. Energy Level Diagrams for Selected Metal Complexes of Phthalocyanines (a) ZnPc, ${ }^{58,60}$ (b) Various Complexes of Phthalocyanines, $^{59}$ (c) $\mathrm{ZnPc}^{39}$ (d) $\mathrm{AlPcS}_{4}$ from TD DFT Calculations in This Paper

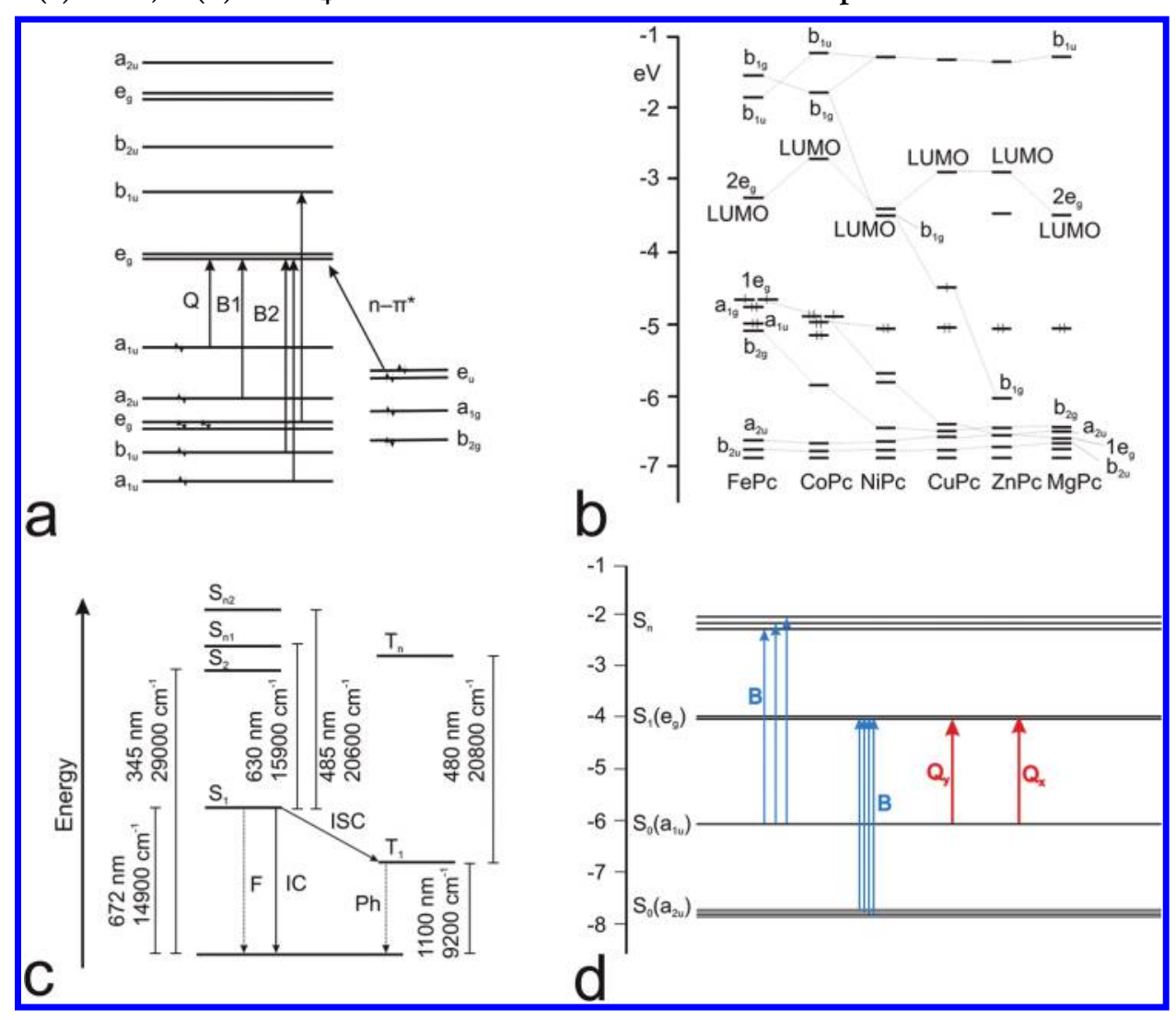

$\Delta A(t)$ presented in the previous section, we need to under stand the details of the electronic transitions in phthalocyanines that are induced and probed by the laser pulses in the pumpprobe experiments. Scheme 3 shows the molecular orbitals in selected phthalocyanines according to the calculations from the literature ${ }^{39,58-60}$ and Kohn-Sham orbitals from our TD DFT calculations (Scheme 3d).

One can see from the Schemes 2 and 3 that the pump pulse at $677 \mathrm{~nm}$ excites the $S_{0}\left(a_{1 u}\right) \rightarrow S_{1}\left(e_{\mathrm{g}}\right)$ transition. The pump pulse at $360 \mathrm{~nm}$ can excite either of the higher excited elec tronic states in the $\mathrm{S}_{0}\left(\mathrm{a}_{1 \mathrm{u}}\right) \rightarrow \mathrm{S}_{\mathrm{n}}\left(\mathrm{b}_{1 \mathrm{u}}\right)$ transition and the $\mathrm{S}_{0}\left(\mathrm{a}_{2 \mathrm{u}}\right) \rightarrow$ $\mathrm{S}_{1}\left(\mathrm{e}_{\mathrm{g}}\right.$ ) transition (a maximum at $350 \mathrm{~nm}$ for $\mathrm{AlPcS}_{4}$ in water and $360 \mathrm{~nm}$ in DMSO). Thus, probing with various spectral components in the visible range makes possible recording of the transient absorption and allows monitoring pf the repopulation of the excited states.

The previous molecular orbitals picture (Scheme 3a) based on the Schaffer, Gouterman, and Davidson considerations ${ }^{58,60}$ suggests that the $360 \mathrm{~nm}$ promotes the $\mathrm{S}_{0}\left(\mathrm{a}_{2 \mathrm{u}}\right) \rightarrow \mathrm{S}_{1}\left(\mathrm{e}_{\mathrm{g}}\right)$ transi tion (B1) and B2 transitions rather than $S_{0}\left(a_{1 u}\right) \rightarrow S_{n}$ transitions to higher excited states. In contrast, the $S_{0}\left(a_{1 u}\right) \rightarrow S_{n}$ transitions have been suggested recently ${ }^{39}$ to be dominant contribution in ZnPc.

Our TD DFT calculations for $\mathrm{AlPcS}_{4}$ (Table 1 and Figure 3d) show that the oscillator strengths for the $S_{0}\left(a_{1 u}\right) \rightarrow S_{1}\left(e_{g}\right)$ (Q transition) are $f=0.3830\left(\mathrm{Q}_{y}\right)$ and $0.3859\left(\mathrm{Q}_{x}\right)$. For the $\mathrm{S}_{0}\left(\mathrm{a}_{2 \mathrm{u}}\right) \rightarrow \mathrm{S}_{1}\left(\mathrm{e}_{\mathrm{g}}\right)$ transition, the oscillator strength is $f=0.1452$. The $\mathrm{B}$ band consists of a few transitions from lower lying orbitals of the ground state to $S_{1}\left(e_{\mathrm{g}}\right)$ with $f$ up to 0.3041 (all transitions are gathered in Table 1). However, the transitions to the second excited state $S_{0}\left(a_{1 u}\right) \rightarrow S_{2}\left(b_{1 u}\right)$ and to higher excited states $S_{0}\left(a_{1 u}\right) \rightarrow S_{n}$ have similar oscillator strengths. Thus, the $B$ band originates both from the inner molecular orbitals to the first excited state $S_{1}\left(e_{g}\right)$ and from the HOMO orbital $S_{0}\left(a_{1 u}\right)$ to the second excited state $S_{2}\left(b_{1 u}\right)$ as well as to higher excited states $S_{n}$. It indicates that the pump pulse at $360 \mathrm{~nm}$ excites both the first excited electronic state in the $S_{0}\left(a_{2 u}\right) \rightarrow S_{1}\left(e_{g}\right)$ transition and the higher excited states in the $S_{0}\left(a_{1 u}\right) \rightarrow S_{2}\left(b_{1 u}\right)$ and the $S_{0}\left(a_{1 u}\right) \rightarrow S_{n}$ transitions. The energy difference between $S_{n}$ and $S_{2}$ is only $1033 \mathrm{~cm}^{-1}$. Although much higher than the thermal energy $k T$, the energy separation corresponds to the vibrational energy. Thus, the nonradiative energy dissipation may occur via energy relaxation between the vibrational states.

The TD DFT results presented so far determine interpre tation of electronic dynamics obtained from our time resolved experimental data. Indeed, the $\mathrm{S}_{0}\left(\mathrm{a}_{2 \mathrm{u}}\right) \rightarrow \mathrm{S}_{1}\left(\mathrm{e}_{\mathrm{g}}\right)$ transition pumped by $360 \mathrm{~nm}$ promotes the molecules to the same state as pumping at $677 \mathrm{~nm}$ for the $\mathrm{S}_{0}\left(\mathrm{a}_{1 \mathrm{u}}\right) \rightarrow \mathrm{S}_{1}\left(\mathrm{e}_{\mathrm{g}}\right)$ transition. Therefore, both pumping wavelengths should demonstrate similar electronic dynamics of $\mathrm{AlPcS}_{4}$. In contrast, the $\mathrm{S}_{0}\left(\mathrm{a}_{1 \mathrm{u}}\right)$ $\rightarrow S_{n}$ transition pumped by $360 \mathrm{~nm}$ should result in different dynamics than that observed for the $S_{0}\left(a_{1 u}\right) \rightarrow S_{1}\left(e_{g}\right)$ transition pumped by $677 \mathrm{~nm}$.

The picture that emerges from the results presented in the paper is the following. The dynamics of $\mathrm{AlPcS}_{4}$ reveals four different time scales with the time constants of 115-500 fs, 212 ps, and 150-500 ps. The fast femtosecond component has been also reported in the literature. ${ }^{39,59,61}$ Savolainen et al. ${ }^{39}$ have assigned the shortest time constant to inertial response of solvation. Fournier et al. ${ }^{61}$ have assigned a constant of $<210 \mathrm{fs}$ observed in NiPc and in $\mathrm{CuPc}$ to the lifetime $\mathrm{S}_{2} \rightarrow \mathrm{S}_{1}$ internal conversion. Rao et al. ${ }^{41}$ have assigned the time constant $<170$ fs 
Table 1. Calculated Excitation Energies, Oscillator Strengths $f>0.1$, Kohn-Sham Orbital Contributions to Transitions, and the Largest Coefficients of CI Expansion

\begin{tabular}{|c|c|c|c|c|c|}
\hline & $E, \mathrm{eV}$ & $\lambda, \mathrm{nm}$ & $f^{a}$ & contributions $^{b}$ & coefficient \\
\hline \multirow[t]{28}{*}{$\mathrm{AlPcS}_{4}$} & 1.9875 & 623.81 & 0.3830 & $219 \rightarrow 229$ & 0.10580 \\
\hline & & & & $221 \rightarrow 229$ & 0.11607 \\
\hline & & & & $222 \rightarrow 229$ & 0.10862 \\
\hline & & & & $\begin{array}{l}227(\text { HOMO }) \rightarrow 228 \\
\quad(\text { LUMO })\left(S_{0}\left(a_{1 u}\right)\right. \\
\left.\rightarrow S_{1}\left(e_{g}\right)\right)\end{array}$ & 0.59031 \\
\hline & & & & $\begin{array}{l}227(\text { HOMO }) \rightarrow 229 \\
\quad\left(\mathrm{~S}_{0}\left(\mathrm{a}_{1 \mathrm{u}}\right) \rightarrow \mathrm{S}_{1}\left(\mathrm{e}_{\mathrm{g}}\right)\right)\end{array}$ & 0.12058 \\
\hline & 1.9949 & 621.50 & 0.3859 & $219 \rightarrow 228$ & 0.10102 \\
\hline & & & & $221 \rightarrow 228$ & 0.12107 \\
\hline & & & & $222 \rightarrow 228$ & 0.12827 \\
\hline & & & & $\begin{array}{l}227(\mathrm{HOMO}) \rightarrow 228 \\
\quad\left(\mathrm{~S}_{0}\left(\mathrm{a}_{1 \mathrm{u}}\right) \rightarrow \mathrm{S}_{1}\left(\mathrm{e}_{\mathrm{g}}\right)\right)\end{array}$ & 0.12001 \\
\hline & & & & $\begin{array}{l}227(\mathrm{HOMO}) \rightarrow 229 \\
\quad\left(\mathrm{~S}_{0}\left(\mathrm{a}_{1 \mathrm{u}}\right) \rightarrow \mathrm{S}_{1}\left(\mathrm{e}_{\mathrm{g}}\right)\right)\end{array}$ & 0.59097 \\
\hline & 3.5054 & 353.69 & 0.1452 & $218 \rightarrow 229$ & 0.11303 \\
\hline & & & & $219 \rightarrow 229$ & 0.35226 \\
\hline & & & & $220 \rightarrow 228$ & 0.10412 \\
\hline & & & & $220 \rightarrow 229$ & 0.20897 \\
\hline & & & & $221 \rightarrow 229$ & 0.42233 \\
\hline & & & & $222 \rightarrow 229$ & 0.10918 \\
\hline & & & & $223 \rightarrow 228$ & 0.14080 \\
\hline & & & & $224 \rightarrow 229$ & 0.12435 \\
\hline & & & & $\begin{array}{l}226 \rightarrow 229 \\
\left.\quad S_{1}\left(e_{g}\right)\right)\end{array}$ & 0.12200 \\
\hline & & & & $\begin{array}{l}227(\text { HOMO }) \rightarrow 231 \\
\left(S_{0}\left(a_{1 u}\right) \rightarrow S_{n}\right)\end{array}$ & 0.10268 \\
\hline & 3.5201 & 352.21 & 0.1332 & $219 \rightarrow 228$ & 0.12967 \\
\hline & & & & $220 \rightarrow 228$ & 0.13796 \\
\hline & & & & $221 \rightarrow 228$ & 0.13288 \\
\hline & & & & $221 \rightarrow 229$ & 0.12931 \\
\hline & & & & $222 \rightarrow 228$ & 0.25215 \\
\hline & & & & $223 \rightarrow 229$ & 0.11626 \\
\hline & & & & $\begin{array}{l}227(\mathrm{HOMO}) \rightarrow 230 \\
\left(\mathrm{~S}_{0}\left(\mathrm{a}_{1 \mathrm{u}}\right) \rightarrow \mathrm{S}_{\mathrm{n}}\right)\end{array}$ & 0.18964 \\
\hline & & & & $\begin{array}{l}227(\text { HOMO }) \rightarrow 231 \\
\left(S_{0}\left(a_{1 u}\right) \rightarrow S_{n}\right)\end{array}$ & 0.46735 \\
\hline
\end{tabular}

\begin{tabular}{|c|c|c|c|c|}
\hline$E, \mathrm{eV}$ & $\lambda, \mathrm{nm}$ & $f^{a}$ & contributions $^{b}$ & coefficient \\
\hline \multirow[t]{10}{*}{3.5488} & 349.37 & 0.3041 & $215 \rightarrow 228$ & 0.14721 \\
\hline & & & $219 \rightarrow 229$ & 0.12782 \\
\hline & & & $220 \rightarrow 228$ & 0.25495 \\
\hline & & & $220 \rightarrow 229$ & 0.25545 \\
\hline & & & $221 \rightarrow 228$ & 0.32581 \\
\hline & & & $221 \rightarrow 229$ & 0.10732 \\
\hline & & & $222 \rightarrow 228$ & 0.19750 \\
\hline & & & $222 \rightarrow 229$ & 0.13936 \\
\hline & & & $\begin{array}{l}227(\text { HOMO }) \rightarrow 230 \\
\left(S_{0}\left(a_{1 u}\right) \rightarrow S_{n}\right)\end{array}$ & 0.14420 \\
\hline & & & $\begin{array}{l}227(\text { HOMO }) \rightarrow 232 \\
\quad\left(S_{0}\left(a_{1 u}\right) \rightarrow S_{n}\right)\end{array}$ & 0.20454 \\
\hline \multirow[t]{9}{*}{3.6569} & 339.04 & 0.2948 & $213 \rightarrow 228$ & 0.26536 \\
\hline & & & $214 \rightarrow 229$ & 0.19537 \\
\hline & & & $215 \rightarrow 229$ & 0.10117 \\
\hline & & & $218 \rightarrow 229$ & 0.13844 \\
\hline & & & $219 \rightarrow 229$ & 0.36646 \\
\hline & & & $220 \rightarrow 228$ & 0.15522 \\
\hline & & & $221 \rightarrow 229$ & 0.24452 \\
\hline & & & $222 \rightarrow 229$ & 0.17421 \\
\hline & & & $\begin{array}{l}227(\text { HOMO }) \rightarrow 232 \\
\quad\left(S_{0}\left(a_{1 u}\right) \rightarrow S_{n}\right)\end{array}$ & 0.10975 \\
\hline \multirow[t]{7}{*}{3.9651} & 312.69 & 0.1932 & $211 \rightarrow 229$ & 0.12158 \\
\hline & & & $212 \rightarrow 229$ & 0.13335 \\
\hline & & & $213 \rightarrow 228$ & 0.36666 \\
\hline & & & $213 \rightarrow 229$ & 0.39653 \\
\hline & & & $216 \rightarrow 228$ & 0.13379 \\
\hline & & & $219 \rightarrow 228$ & 0.11170 \\
\hline & & & $\begin{array}{l}227(\text { HOMO }) \rightarrow 234 \\
\quad\left(S_{0}\left(a_{1 u}\right) \rightarrow S_{n}\right)\end{array}$ & 0.11170 \\
\hline \multirow[t]{6}{*}{3.9731} & 312.06 & 0.1375 & $211 \rightarrow 228$ & 0.14594 \\
\hline & & & $212 \rightarrow 228$ & 0.17506 \\
\hline & & & $213 \rightarrow 228$ & 0.37033 \\
\hline & & & $213 \rightarrow 229$ & 0.37569 \\
\hline & & & $216 \rightarrow 229$ & 0.11856 \\
\hline & & & $219 \rightarrow 229$ & 0.10609 \\
\hline
\end{tabular}

${ }^{a}$ Oscillator strength. ${ }^{b}$ Orbital number.

to phase relaxation of $S_{n}$ states. Our results demonstrate that the fast femtosecond component is not related to the solvation dynamics as the time constants are almost identical in both solvents, water and DMSO. We have obtained results showing that the initial decays of the signal at $500 \mathrm{~nm}$ are monoexponential and can be fitted with a time constant of $244 \pm 98 \mathrm{fs}$ in water and $155 \pm 51 \mathrm{fs}$ in DMSO. The initial decays of the signal at $572 \mathrm{~nm}$ are monoexponential and can be fitted with a time constant of $560 \pm 94 \mathrm{fs}$ in water and $480 \pm$ $384 \mathrm{fs}$ in DMSO. The recovery of the bleach in water at $752 \mathrm{~nm}$ is found to be biexponential and is fitted with time constants of $490 \pm 70$ fs and $3.79 \pm 1.25$ ps for pumping with $677 \mathrm{~nm}$ and $480 \pm 60$ fs and $2.33 \pm 0.81$ ps for pumping with $360 \mathrm{~nm}$. It indicates that the fast femtosecond component does not depend on solvent. Thus, we find it unlikely to assign it to inertial response of solvation. We have assigned the femto second component to vibrational wavepacket dynamics of higher electronic states of $\mathrm{AlPcS}_{4}$ immediately upon excitation.

The time components in the range of $2-25$ ps obtained for $\mathrm{AlPcS}_{4}$ at different wavelengths are similar to those reported in the literature for many phthalocyanines. ${ }^{23,39,59}$ Savolainen et al. ${ }^{39}$ have assigned the time constant of 2.5 ps to dielectric response of solvation. Rao et al. ${ }^{41}$ have assigned the time constant of $3-5$ ps to vibrational relaxation. Howe and Zhang ${ }^{23}$ have assigned the time constant of 10 ps to the lifetime for the $S_{2} \rightarrow S_{1}$ internal conversion, which seems rather long. The sudden rise at $572 \mathrm{~nm}$ followed by a decay (Figure 6a) is found to be biexponential and is fitted with time constants of $3.51 \pm$ 0.50 and $220 \pm 25$ ps in water and 3.44 and $115 \pm 95$ ps in DMSO, indicating that the signals observed in the range of 500-572 nm demonstrate similar features of dynamics in both solvents. If dielectric response of solvation governed the dynamics of $\mathrm{AlPcS}_{4}$, high dielectric constant solvents such as water $(\varepsilon=80)$ and DMSO $(\varepsilon=48)$ would produce distinctive features of dynamics in contrast to the obtained results. Thus, we have assigned the time constants in the range of $2-25$ ps observed in our results to vibrational relaxation.

The longest time constants in the range of 150-500 ps have been assigned to the decay from $S_{1}$ to the ground state, as suggested by Howe and Zhang, because we have found dynamics occurring on a similar time scale as that in ref 23 . We have found for $\mathrm{AlPcS}_{4}$ in water time constants of 469 and 299 ps for the decay of the positive signals (ESA) at $500 \mathrm{~nm}$ for pumping at 677 and $360 \mathrm{~nm}$, respectively. Therefore, we have assigned them to the decay from $S_{1}$ to the ground state. We have found no evidence of the nanosecond component in the 
dynamics at 500 and $572 \mathrm{~nm}$, in contrast to the results of Savolainen et al. ${ }^{39}$ who obtained the component of $7 \mathrm{~ns}$ for $\mathrm{ZnPc}$ at $480 \mathrm{~nm}$.

\section{CONCLUSIONS}

The excited state dynamics of $\mathrm{AlPcS}_{4}$ have been studied in both aqueous and organic (DMSO) solutions by fluorescence and pump-probe transient absorption laser spectroscopy, providing information about the events occurring o $\mathrm{n}$ time scales ranging from femtoseconds to nanoseconds. The dynamics in both solvents is dominated primarily by monomeric molecules up to very high concentrations of $10^{-3} \mathrm{M}$. We have found that the fast dynamics of $\mathrm{AlPcS}_{4}$ in water and $\mathrm{DMSO}$ reveals three time scales, $115-500 \mathrm{fs}, 2-25 \mathrm{ps}$, and $150-500$ ps. The shortest time constants have been assigned to vibrational wavepacket dynamics, the few picosecond component has been assigned to vibrational relaxation in the excited electronic states, and the 150-500 ps components represent the decay from $S_{1}$ to the ground state. The experimental and theoretical treatment proposed in this paper provides a basis for a substantial revision of the commonly accepted interpretation of the Soret transition (B transition) that exists in the literature. The Soret band in the UV absorption spectrum of phthalocyanines originates both from the electronic transitions from the inner molecular orbitals to the first excited state $S_{1}\left(e_{g}\right)$ and from the HOMO orbital $S_{0}\left(a_{1 u}\right)$ to the second excited state $S_{2}\left(b_{1 u}\right)$ as well as to higher excited states $S_{n}$.

\section{AUTHOR INFORMATION}

\section{Corresponding Author}

*E mail: abramczy@mitr.p.lodz.pl.

\section{Notes}

The authors declare no competing financial interest.

\section{ACKNOWLEDGMENTS}

The research work has been financed from funds for science in 2010-2012 as a research project "Preparation and implemen tation of new fields of studies in response to the needs of a contemporary labour market and requirements of knowledge based economy" UDA POKL.04.01.01. $00213 / 0800$ and NCN Grant Nr 3845/B/T02/2009/37.

\section{REFERENCES}

(1) Dolmans, D. E.; Fukumura, D.; Rakesh, K. Nat. Rev. Cancer 2003, $3,380-387$.

(2) Vrouenraets, M. B.; Visser, G. W. M.; Snow, G. B.; van Dongen, G. A. M. S. Anticancer Res. 2003, 23, 505-522.

(3) Henderson, B. W.; Dougherty, T. J. Photochem. Photobiol. 1992, $55,145-57$.

(4) Boyle, R. W.; Dolphin, D. Photochem. Photobiol. 1996, 64, 469485.

(5) Brown, S. B.; Brown, E. A.; Walker, I. Lancet Oncol. 2004, 5, 497-508.

(6) Wang, X. L.; Wang, H. W.; Yuan, K. H.; Li, F. L.; Huang, Z. Photochem. Photobiol. Sci. 2011, 10, 704-711.

(7) Maduray, K.; Karsten, A.; Odhav, B.; Nyokong, T. J. Photochem. Photobiol., B 2011, 103 (2), 98-104.

(8) Lui, H.; Anderson, R. R. Arch. Dermatol. 1992, 128 (12), 16311636.

(9) Stuchinskaya, T.; Moreno, M.; Cook, M. C.; Edwards, D. R.; Russell, D. A. Photochem. Photobiol. Sci. 2011, 10, 822-831.

(10) Whitacre, C. M.; Satoh, T. H.; Xue, L.; Gordon, N. H.; Oleinick, N. L. Cancer Lett. 2002, 179 (1), 43-49.
(11) Moura, V.; Lacerda, M.; Figueiredo, P.; Corvo, M. L.; Cruz, M. E. M.; Soares, R.; Pedroso de Lima, M. C.; Simões, S.; Moreira, J. N. Breast Cancer Res. Treat. 2011, PMID: 21805188.

(12) Witjes, M. J.; Speelman, O. C.; Nikkels, P. G.; Nooren, C. A.; Nauta, J. M.; van der Holt, B.; van Leengoed, H. L.; Star, W. M.; Roodenburg, J. L. Br. J. Cancer 1996, 73 (5), 573-580.

(13) Austwick, M.; Woodhams, J. H.; Chalau, V.; Mosse, C. A.; Eliot, C.; Lovat, L. B.; MacRobert, A. J.; Bigio, I. J.; Bown, S. G. J. Innovative Opt. Health Sci. 2011, 97, 111.

(14) Rosenkranz, A. A.; Jans, D. A.; Sobolev, A. S. Immunol. Cell Biol. 2000, 78, 452-464.

(15) Dini, D.; Hanack, M. J. Porphyrins Phthalocyanines 2004, 8, 915.

(16) Tokumaru, K.Phthalocyanines; Shirai, H., Kobayashi, N., Edf;

IPCL Tokyo, 1997; p 170.

(17) Prasad, D. R.; Ferraudi, G. Inorg. Chem. 1982, 21, 2967.

(18) Muralidharan, S.; Ferraudi, G. J. Phys. Chem. 1983, 87, 4877.

(19) Ferraudi, G.; Muralidharan, S. Inorg. Chem. 1983, 22, 1369.

(20) Kaneko, Y.; Arai, T.; Sakarugi, H.; Tokumaru, K.; Pac, C. J. Photochem. Photobiol., A 1996, 97, 155.

(21) Kaneko, Y.; Nishimura, Y.; Arai, T.; Sakuragi, H.; Tokumaru, K.; Matsunaga, D. J. Photochem. Photobiol., A 1995, 89, 37.

(22) Kaneko, Y.; Nishimura, Y.; Takane, N.; Arai, T.; Sakuragi, H.; Tokumaru, K.; Kobayashi, N.; Matsunaga, D. J. Photochem. Photobiol., A 1997, 106, 177.

(23) Howe, I.; Zhang, J. Z. J. Phys. Chem. A 1997, 101, 3207.

(24) Ruckmann, I.; Zeug, A.; Herter, R.; Roder, B. Photochem. Photobiol. 1997, 66, 576.

(25) Chahraoui, D.; Valet, P.; Kossanyi, J. Res. Chem. Intermed. 1992, 17, 219.

(26) Kobayashi, N.; Ashida, T.; Osa, T. Chem. Lett. 1992, 10, 20312031.

(27) Kobayashi, N.; Lever, A. B. P. J. Am. Chem. Soc. 1987, 109, 7433.

(28) Kobayashi, N.; Lam, H.; Nevin, W. A.; Leznoff, C. C.; Koyama, T.; Monden, A.; Shirai, H. J. Am. Chem. Soc. 1994, 116, 879.

(29) Kobayashi, N.; Togashi, M.; Osa, T.; Ishii, K.; Yamauchi, S.; Hino, H. J. Am. Chem. Soc. 1996, 118, 1073.

(30) Zhong, Q.; Wang, Z.; Liu, Y.; Zhu, Q.; Kong, F. J. Chem. Phys. 1996, 105, 5377.

(31) Strickler, S. J.; Berg, R. A. J. Chem. Phys. 1962, 37, 814.

(32) Gilbert, A.; Baggott, J. Essentials of Molecular Photochemistry; Blackwell: Oxford, U.K., 1991; p 98.

(33) Rosenthal, I.; Krishna, C. M.; Riesz, P.; Ben Hur, E. Radiat. Res. 1989, 107, 136.

(34) Tokumaru, K. J. Porphyrins Phthalocyanines 2001, 5, 77.

(35) FitzGerald, S.; Farren, C.; Stanley, C. F.; Beeby, A.; Bryce, M. R. Photochem. Photobiol. Sci. 2002, 1, 581-587.

(36) Brożek Płuska, B.; Jarota, A.; Kurczewski, K.; Abramczyk, H. J. Mol. Struct. 2009, 924-926, 338-334.

(37) Brożek Płuska, B.; Czajkowski, W.; Kurczewska, M.; Abramczyk, H. J. Mol. Liq. 2008, 141, 140-144.

(38) Abramczyk, H.; Brożek Płuska, B.; Kurczewski, K.; Kurczewska, M.; Szymczyk, I.; Krzyczmonik, P.; Błaszczyk, T.; Scholl, H.; Czajkowski, W. J. Phys. Chem. A 2006, 110 (28), 8627-8636.

(39) Savolainen, J.; van der Linden, D.; Dijkhuizen, N.; Herek, J. L. J. Photochem. Photobiol., A 2008, 196, 99-105.

(40) Ho, Z. Z.; Peyghambarian, N. Chem. Phys. Lett. 1988, 148, 107111.

(41) Rao, S. V.; Rao, D. N. J. Porphyrins Phthalocyanines 2002, 6, 233-237.

(42) Hosokawa, Y.; Yashiro, M.; Asahi, T.; Fukumura, H.; Masuhara, H. Appl. Surf. Sci. 2000, 154-155, 192-195.

(43) Ma, G.; He, J.; Kang, C.; Tang, S. Chem. Phys. Lett. 2003, 293299.

(44) Hush, N. S.; Woolsey, I. S. Mol. Phys. 1971, 21, 465-474.

(45) Kobayashi, N.; Lever, A. B. P. J. Am. Chem. Soc. 1987, 109, 7433.

(46) Kane, A. R.; Sullivan, J. F.; Kenny, D. H.; Kenney, M. E. Inorg. Chem. 1970, 9, 1445-1448.

(47) Dhami, S.; Cosa, J. J.; Bishop, S. M.; Phillips, D. Langmuir 1996, $12,293$. 
(48) Ostler, R. B. An Investigation of Intracellular PDT Mechanisms.

Ph.D. Thesis, University of London. 1997.

(49) Liu, Y.; Shigara, K.; Hara, M.; Yamada, A. J. Am. Chem. Soc. 1992, 113, 440-443.

(50) Ford, W. E.; Rihter, B. D.; Kenney, M. E.; Rodgers, M. A. J. Photochem. Photobiol. 1989, 50, 277.

(51) Abramczyk, H.; Szymczyk, I. J. Pure Appl. Chem. 2004, 76, 183187.

(52) Abramczyk, H.; Szymczyk, I. J. Mol. Liq. 2004, 110, 51-56.

(53) Abramczyk, H.; Szymczyk, I.; Waliszewska, G.; Lebioda, A. J. Phys. Chem. A 2004, 108, 264-274.

(54) Jarota, A.; Brozek Pluska, B.; Czajkowski, W.; Abramczyk, H. J. Phys. Chem. C 2011, 115 (50), 24920-24930.

(55) Frisch, M. J.; Trucks, G. W.; Schlegel, H. B.; Scuseria, G. E.; Robb, M. A.; Cheeseman, J. R.; Montgomery, J. A.; Vreven, T.; Kudin, K. N.; Burant, J. C. et al. Gaussian 03; Gaussian Inc., Pittsburgh, PA, 2003.

(56) Harriman, A.; Richoux, M. J. Photochem. 1980, 14, 253.

(57) Oddos Marcel, L.; Madeore, F.; Bock, A.; Neher, D.; Ferencz, A.; Rengel, H.; Wegner, G.; Kryschi, C.; Trommsdorff, H. P. J. Phys. Chem. 1996, 100, 11850.

(58) Schaffer, A. M.; Gouterman, M.; Davidson, E. R. Theor. Chim. Acta 1973, 30, 9.

(59) Liao, M. S.; Scheiner, S. J. Chem. Phys. 2001, 114, 9780.

(60) Mack, J.; Stillman, M. J. J. Am. Chem. Soc. 1994, 116, 12921304.

(61) Fournier, M.; Pepin, C.; Houde, D.; Ouellet, R.; van Lier, J. E. Photochem. Photobiol. Sci. 2004, 3, 120. 